ness in the scientist and technologist that has been a wide source of complaint and criticism. The fact that most universities are already known to agree with the proposals is promising, but it is to be hoped that those who have expressed opposition in principle will not fail to como into line. Simultaneously, with the re-examination of syllabus in the science subjects themselves, it offers an opportunity of improvement that is unlikely to recur but which if seized with vision and determination could transform the whole training of the science graduate. Any university should hesitate before raising obstacles or imposing requirements which could cause the opportunity to be missed.

\title{
THE MELLON INSTITUTE
}

$\mathrm{T}$ HE annual report of the Mellon Institute for the year ended February 28, 1962*, records expenditure of 5.9 million dollars on independent and sponsored research. At the end of the year the Institute's staff was 561, and 362 professional and technical members were reporting on some 100 investigations. A list of publications of members during 1961 other than patents or periodicals or reports that do not appear in the open literature is included. Eighteen appointments at the level of Fellow were made during the year, half of whom joined Independent and half Sponsored Research. The Research Services of the Institute in its Instruments Section placed emphasis on systems which completely programme experimental procedures and increase the amount and accuracy of the information recorded. An instrument was constructed for the automatic recording of additives during redox measurements, a lowtemperature $\left(40^{\circ} \mathrm{K}\right.$ to ambient) controller designed and built for the magnetic susceptibility programme and a circuit design of the instrument and servo system completed for a 'hot hardness testor'. In the Physicochemical Section the study of adsorbed organic molecules on catalysis by infra-red spectroscopy was extended, and a study initiated to find a correlation, if any, between the presence of trace elements and the occurrence of cataracts of the eye. The Microbiology and Microscopy Section completed a study of microbiological sludge inhibitors for jet fuels.

Under independent research, the report records continuing work on the detailed characteristics and distribution of plasma and red-cell hydrolytic enzymes, with special emphasis on the enzymes of the circulating blood which attack the hypotensive polypeptides, bradykinin and kallidin. Investigations are being continued on the interrelation between metabolites of $p$-aminobenzoic acid and aniline hydroxylation by resting cells of acid-fast bacteria, and completion of an electron microscopical study of ribonucleic acid from tobacco mosaic virus is reported. In organic chemistry, besides investigations of the acylamidines, the rotational isomerism in mono- and di-alkylpropenes of the types $R \cdot \mathrm{CH}_{2} \cdot \mathrm{CH}=\mathrm{CH}_{2}$ and $R_{2} \mathrm{CH} . \mathrm{CH}=\mathrm{CH}_{2}$ has been investigated by nuclear magnetic resonance spectroscopy, and a five-step synthesis developed of $1: 2: 3$-triphenyl-4:5-benzpentalene. Efforts are being directed to develop general routes for the synthesis of branched polymers of the star type and of the comb type, and the stereochemical structures of polymers prepared by free-radical polymerization of methyl methacrylate have been computed from high-resolution nuclear

* Mellon Institute. Annual Report, 1961. Pp. 36. (Pittsburgh, Pa.: Mellon Institute, 1962.) magnetic resonance spectra measured at room temperature in chloroform solutions. Preliminary experiments have been made on the effects of heterogeneity in chain length, in chain branching, and of diluent on the relation between molecular weight and flow of high polymers in bulk or in concentrated solution. The basic studies in co-ordination chemistry led to the discovery of several unusual complex compounds, including a univalent iridium compound which reacts at normal conditions with a number of molecules commonly regarded as relatively inert. In physical chemistry, low-frequency infra-red spectroscopy and the vibrational spectra of inorganic substances have been particularly fruitful fields, and in radiation chemistry the electron-spin-resonance studies of radicals have been extended to a variety of hydrocarbons. Photochemical investigations largely focused on such systems as phosgene-olefine mixtures, 1 : 2-dichloroethylene and ethyl and vinyl iodides. Work continued on a mathematical theory of fluid behaviour within which many fluid-flow problems can be solved, and attempts are being made to find exact solutions for the steady-state Schrödinger equation for systems of two or more electrons in the potential field existing in an arbitrary molecular framework.

In metal physics, low-temperature ealorimetry studies are in progress to obtain more reliable data for the copper-zine and related binary systems. The study of stacking-fault probabilities in noble metal alloys has been extended to the silver-cadmium system, where a linear relation between the faulting probability and composition has been observed over compositions containing $0-30$ atomic percentage of cadmium.

A group of investigations concerned with public welfare range from air purification, the processes involved in the deterioration of artists' materials, toxicity of new organic chemicals, industrial hygiene, mine acid control, steel protection and water resources. Notes are also included on progress in projects concerned with the development of solid catalysts from bono products for organic reactions; ceramic chemicals; aspects of forming and treating structural clay products and performance of plant scale equipment; starch-based chemicals as textile warp sizes; the performance of industrial fabrics from felt; forrous alloys; a hydrogonation method for determining low concentrations of organic sulphur in natural gas; the chemistry of petroleum genesis; the fundamental nature of the activity of catalysts; studies of metal surfaces in hydrogenation; silicones; the synthesis of phosphonitriles; and the degree of susceptibility of selected high-strength case steels for rocket motors and other alloys to stress-corrosion cracking. 